\title{
HUMANIZAÇÃO HOSPITALAR: A CONTRIBUIÇÃO DO PROFISSIONAL DE LAZER EM INSTITUIÇÕES PSIQUIÁTRICAS
}

\author{
Driele Cendon Trindade \\ Graduada em Lazer e Qualidade de Vida - CEFET-RN \\ E-mail: drieleee@yahoo.com.br
}

\section{Recebido em fevereiro de 2006 e aceito em maio de 2006}

\begin{abstract}
RESUMO
Este estudo situa-se dentro de uma necessidade de analisar as possibilidades de contribuição de um profissional de lazer em instituições hospitalares psiquiátricas, por ser um grupo segregado da sociedade, estimulando a inclusão social, através de vivências de lazer. Assim, tem-se como objetivo diagnosticar as contribuições no processo de humanização hospitalar, possibilitando os interesses culturais do lazer - cultural, social, físico, intelectual e manual - aos pacientes portadores de transtorno mental de um hospital do município do Natal-RN, melhorando a socialização e contribuindo para a melhora da qualidade de vida dos mesmos. Este estudo é referenciado por explanações dos conteúdos envolvidos, partindo da idéia de humanização através do lazer, o processo de humanização hospitalar, seguindo para a trajetória da doença, a reforma psiquiátrica e principalmente a contribuição do profissional de lazer no processo dessa humanização, baseando-se nas principais pesquisas que estão sendo feitas na área de psiquiatria em todo país e de autores ligados diretamente à área do Lazer como Marcellino, Dumazedier e Werneck. A metodologia utilizada para a concretização do mesmo foi o estudo de caso através de observações diretas não-participantes e assistemáticas, por meio de um estudo detalhado da convivência semanal durante o período de out 2004/maio 2005 com o cotidiano hospitalar da instituição psiquiátrica. Através das análises realizadas, pode-se perceber que o papel do profissional de lazer no processo de humanização hospitalar fica caracterizado pela necessidade de democratizar as atividades de lazer contribuindo para todo um quadro social oriundo de uma revolução do mesmo. Esta iniciativa além de abrir novos rumos para o profissional de lazer, contribuirá para fomentar as pesquisas sobre lazer na área de saúde que são escassas.
\end{abstract}

Palavras chave: Lazer, Humanização Hospitalar, Saúde Mental.

\section{HOSPITAL HUMANIZATION: THE CONTRIBUTION OF THE LEISURE PROFESSIONAL IN PSYCHIATRIC INSTITUTIONS}

\begin{abstract}
This study is placed inside of a necessity to analyze the possibilities of contribution from a professional of leisure in psychiatric hospital institutions, being a segregated group of the society, stimulating the social inclusion, through leisure experiences. Thus, it is had as objective to diagnosis the contributions in the process of hospital humanization, making possible the cultural interests of the leisure - cultural, social, physical, intellectual and manual - to the patients carrying mental upheaval. Through a study of case in a hospital of the city of the Natal-RN, improving the socialization and contributing for the improvement of the life quality of the same ones. This study is referenced by communications of the
\end{abstract}


involved contents, starting from the idea of humanization through the leisure, the process of hospital humanization, following for the trajectory of the illness, the psychiatric reform and mainly the contribution of the professional of leisure in the process of this humanization, being based on the main research that is being made in the area of psychiatry in all country and on authors directly to the area of the Leisure as Marcellino, Dumazedier and Werneck. The methodology used for the concretion of exactly was the study of case through direct comments not-participants and studied, by means of a study detailed of the weekly living during the 2004/out period of mai/2005 with daily the hospital one of the psychiatric institution. Through the carried through analyses, it can be perceived that the paper of the professional of leisure in the process of hospital humanization is characterized for the necessity to democratize the activities of leisure all contributing for a deriving social picture of a revolution it. This initiative besides opening new routes for the leisure professional, will contribute to foment of the research on leisure in the health area that is scarce.

Keywords: Leisure, Hospital Humanization, Mental Health. 


\section{HUMANIZAÇÃO HOSPITALAR: A CONTRIBUIÇÃO DO PROFISSIONAL DE LAZER EM INSTITUIÇÕES PSIQUIÁTRICAS}

\section{INTRODUÇÃO}

Atualmente percebe-se que as instituições hospitalares são lugares frios, solitários e desprovidos de possibilidades para a vivência do lúdico, do lazer. Dentro dessa "característica" busca-se com este, demonstrar que os pacientes de tais instituições, analisados em um hospital psiquiátrico, devem vivenciar o lazer, pois este tem sido considerado como aliado no tratamento de várias doenças, visto que possui caráter de socialização, tanto entre os pacientes quanto entre os indivíduos que os cercam, como família, amigos, médicos, assistentes, e etc, sendo foco de uma inclusão social.

A prática de atividades com fins lúdicos é constantemente discriminada por outros profissionais e pela própria sociedade, que não percebem as possibilidades de intervenção dos profissionais de lazer em instituições hospitalares, ainda mais como contribuintes na reinserção dos pacientes na sociedade. O profissional de lazer é um articulador e educador, que deve difundir a prática das atividades lúdicas, fazendo com que a socialização se torne mais efetiva e a qualidade de vida dos pacientes melhore na instituição, deixando o caráter de solitário e frio de lado, e ainda, possibilitando ocupar o tempo ocioso dos pacientes fazendo-os vivenciar o lazer em sua plenitude, visto que este é um direito constitucionalmente consagrado, ao mesmo nível de segurança, saúde e educação.

Visando o direito ao lazer, percebe-se que as instituições hospitalares o deixam de lado, não dão devida importância aos benefícios que ele pode trazer e, muitas vezes não o julga necessário num processo de tratamento das doenças. Nesse caso, pesquisou-se como um hospital que tem suas práticas voltadas para o atendimento de clientes portadores de transtorno mental pode usufruir benefícios através dos métodos das vivências de lazer.

O hospital pesquisado possui atendimento rotativo, os pacientes são internados de acordo com a situação e gravidade do transtorno mental sendo tratados. Atualmente, a instituição atende cerca de 200 pacientes/dia; possui um quadro de funcionários desde estagiários, ao quadro de Recursos Humanos. Quanto aos espaços a instituição possui alguns com potencialidades para o lazer, mas sem políticas de animação e atividades contínuas, além das enfermarias feminina e masculina, com uma sala de recreação em ambas; como se percebe não há espaço para que todos os pacientes ocupem seu tempo disponível com alguma atividade, ficando a maioria deles “vagando" pelo pátio em estado de abandono ou dentro das próprias enfermarias.

Portanto, a contribuição do profissional de lazer se faz necessária para mudar esse quadro visível de solidão e frieza de um hospital, uma vez que pacientes portadores de transtorno mental internados não são "inúteis" e nem "improdutivos" como a sociedade costuma analisar, rejeitando-os, mas sim, que precisam de pessoas profissionais e competentes para dar a oportunidade de reflexão interior, e que cada um descubra o que há de melhor em si, e mostrar assim, que eles são capazes de produzir e atuar ainda que não seja de maneira igualitária às pessoas que não sofrem de transtornos psiquiátricos na sociedade.

A metodologia utilizada caracteriza-se como um estudo de caso por se relacionar com as vivências e observações de dados colhidos diretamente com o público-alvo e seu 
pesquisador, referindo-se ao levantamento com mais profundidade de determinado grupo sob os aspectos preestabelecidos no diagnóstico. A pesquisa é de cunho qualitativo e assistemática, tendo abordagem interpretativa de processo contínuo, pois segundo Marconi (2004), propicia a estratégia escolhida, buscando no campo uma relação mais estreita com a realidade do grupo a ser estudado, e ainda identificando os fatores que determinam ou que contribuem para a ocorrência de alguns fenômenos, neste caso, os fenômenos lúdicos. A pesquisa realizada baseia-se em observações não-participante do ponto de vista do pesquisador, em um hospital psiquiátrico sob o período de coleta de dados de outubro/2004 a maio/2005.

Para o profissional de Lazer é importante conhecer a realidade do grupo em que irá atuar, portanto, procurou-se explanar alguns campos e destacar algumas considerações a respeito da doença, como a trajetória da doença, a reforma psiquiátrica, e principalmente, a contribuição do profissional de lazer em instituições psiquiátricas, além de fazer uma abordagem sobre o lazer na sociedade, e como se torna um instrumento de humanização através de suas vivências.

Do ponto de vista acadêmico a relevância do estudo é necessária, tanto para avaliar uma das possibilidades de atuação do profissional de lazer, bem como, o mesmo, como formador de opinião tem o dever de incentivar a inclusão de todos os indivíduos na sociedade, democratizando o acesso ao lazer, e ainda, abrir novos rumos e possibilidades de pesquisas dentro da área do lazer, incentivando também a produção acadêmica relacionado aos estudos do lazer no campo da saúde, visto que é escassa a bibliografia nesta área, considerando que o lazer também é promotor da qualidade de vida.

Diante do exposto, a problemática do estudo apresenta-se pela da análise de que o hospital sempre foi e sempre será um lugar onde a maioria das pessoas não gostaria de permanecer e nem de visitar. Nesse contexto, quais as possibilidades de contribuição dos profissionais de lazer para melhorar a estadia de pessoas que necessitam estar neste local, principalmente para os pacientes que precisam ficar internos?

\section{O PROCESSO DE HUMANIZAÇÃO}

O conceito básico que se remete quando a palavra humanização surge geralmente é o torna-se humano, pensar no próximo, como fonte de poder amenizar tensões e conflitos, acentuar as ações solidárias, uma visão mais comprometida com as relações, substituir o maquinário por trabalho humano, garantir a sua dignidade ética, democratizar ações, tornar uma atividade em benefício comum, e etc, muito embora várias idéias sejam pensadas para se chegar a tais conclusões. Enquanto qualidade de vida remete muitas idéias, como considerar o modo de o indivíduo encarar a realidade e adaptar-se a ela, equilibrar sua saúde intelectual e física; melhorar o rendimento ou produtividade em vários ramos, atender as necessidades básicas do indivíduo e do meio em que vive relacionado às questões de perspectivas de cada um, e etc.

Assim, a qualidade de vida está tanto ligada às questões pessoais, quanto profissionais, sociais e ambientais; ter qualidade de vida requer estar de bem consigo mesmo, independente de poder aquisitivo, de nível intelectual, de etnia, de credo ou religião e aproveitar da melhor maneira possível os recursos disponíveis dos indivíduos, como tempo e espaço, entre outros como vários estudiosos da área descrevem. 
Para se entender o processo de humanização através do lazer, é preciso antes de tudo, saber que o lazer é algo essencial na vida dos indivíduos, embora muitos não o considere, e sim o tratam como uma fuga da rotina. O lazer é acessível a todos os indivíduos da sociedade, independente de qualquer distinção que se possa fazer, podendo ser definido como o direito mais democrático que existe, por todos terem a oportunidade de vivenciá-lo, basta que o indivíduo tenha consciência do tempo disponível e encontre nesse tempo dentre os interesses culturais do lazer - manuais, artísticos, físicos, sociais e intelectuais - algo que lhe proporcione prazer e satisfação em vivenciar.

Para o lazer torna-se um direito efetivo na prática, precisa-se acima de tudo ser democratizado, e isso implica em democratizar o espaço da vivência do lazer. Alguns estudos, como Marcellino (1995) apontam que para se pensar em lazer e espaço, muitos remetem ao pensamento de equipamento construído, mas antes disto é preciso rever os conceitos de lazer, que pressupõe principalmente um "tempo disponível”, e para sua vivência, é necessário também um “espaço disponível” - por exemplo, no caso da leitura, que é um interesse intelectual do lazer; o espaço da leitura não é o espaço da casa, ou da biblioteca, ou da escola, mas sim onde o leitor se encontra no texto, se encontra com o outro, com o autor, ou a personagem, e com o mundo que é tratado ali, é vivenciar o universo da própria vivência. E ainda é preciso somar esforços, procurar vencer as barreiras sociais e culturais que restringem a prática do lazer a uma elite social que se preocupa com a acumulação de bens materiais e visualiza o lazer apenas como produto de consumo.

Deve-se educar "para o lazer", aproveitando o potencial das atividades vivenciadas no “tempo disponível”, acelerando o processo de mudança que possibilitará a instalação de uma nova ordem no plano cultural e social - chamada Revolução Cultural do Lazer. As atividades de lazer podem constituir um dos canais possíveis de transformação cultural e moral da sociedade; o lazer pode modificar a realidade de uma casa, rua, bairro, tem a capacidade de transformar o cotidiano em um ambiente onde se possa aproveitar e desfrutar dos benefícios que mesmo pode oferecer contribuindo para a qualidade de vida.

Quando se trata a questão de qualidade de vida relacionada ao lazer Moreira (2001), normalmente, justifica-se o mesmo em nossa sociedade, se agregado a um outro conceito, como se fosse uma "válvula de escape" servindo para amenizar as tensões do dia-a-dia, reposição de forças para no dia seguinte para continuar a jornada de trabalho. Isso se deve a "ressonância social do lazer", ainda não vista como um direito social, e também pertencente à hierarquia de necessidades dos indivíduos, dessa maneira o lazer é sempre marginalizado no processo de construção do "ser", quando na verdade o mesmo deveria fazer parte da sua construção. Como Marcellino (2001) enfatiza, deve-se levar em consideração o lazer, sendo portador de um duplo aspecto educativo - educação para o lazer e educação pelo lazer, considerando não apenas suas possibilidades de descanso e divertimento, mas também de desenvolvimento pessoal e social através de suas vivências.

\section{HUMANIZAÇÃO HOSPITALAR}

\subsection{A Trajetória dos Transtornos Mentais}

O processo de humanização está intimamente ligado à qualidade de vida. Quando se refere ao comportamento dos indivíduos, seu modo de pensar e agir, ao longo dos anos, percebe- 
se que os mesmos se tornaram mais solidários, pensam mais nas questões sociais, em busca do desenvolvimento coletivo, no próximo, assim se estabelece uma relação que também interfere na sua qualidade de vida. Mas não foi sempre assim, a assistência ao ser humano com transtornos mentais tem a sua trajetória histórica marcada por processos de exclusão, isolamento, segregação, e anulação do indivíduo enquanto portador de direitos.

Segundo Tundis (2000), antigamente não se pensava em doença mental, as pessoas que tinham comportamento diferente do habitual, especialmente quando se tornavam agitadas ou agressivas, eram consideradas loucas. E a sociedade, sem compreendê-las, colocava-as em celas ou masmorras, onde eram abandonadas. Em outro momento acreditou-se que essas pessoas estavam possuídas pelo demônio, eram então usadas práticas de exorcismo para expulsá-lo. Enfim, considerava-se que elas haviam perdido sua condição humana; assim, ficavam excluídas, acorrentadas, expostas ao frio e mal-alimentadas.

A partir das idéias do Iluminismo durante a Revolução Francesa no final do século XVIII Igualdade, Liberdade e Fraternidade - e a declaração dos Direitos Humanos, cresceu o movimento de denúncias contra as internações de portadores de transtorno mental; as mortes, as torturas disfarçadas sob a forma de tratamentos médicos, aos quais os indivíduos eram submetidos fizeram com quem alguns médicos, como Pinel na França, Tuke na Inglaterra, Chiaruggi na Itália, Todd nos EUA, entre outros, repensassem e iniciassem um movimento de reforma em seus tratamentos, assim, essa clientela passaria a receber cuidados psiquiátricos sistemáticos, de acordo com Lyra (2004).

Dentre os médicos mencionados, Gondim (2001) coloca que se podem distinguir dois pólos de pensamentos, a do médico Philippe Pinel - pai da psiquiatria - na qual o louco passa a ser visto como um doente que deveria ser submetido a um tratamento, propiciandolhes melhores condições de vida, mas lidava com o tratamento mental como forma de julgamentos, seus gestos eram vigiados, baseados na disciplina rígida. E o outro pólo, formado pelos outros médicos, que transformaram a violência franca em violência velada da ameaça e das privações. Para esses, os "loucos" deveriam aprender a viver na sociedade, e para isso eram ameaçados e maltratados, com o intuito de esses métodos os modificassem. Os pacientes passaram a serem internados em espaços para serem reeducados passando a ter sua vida organizada; eram observados e classificados, para que seus desvios fossem corrigidos, uma concepção que para alguns perdura até hoje.

Em 1793, Pinel realizou a primeira reforma, denunciando as condições desumanas dos asilos da época, propondo uma nova lógica para a tutela: o tratamento moral e educativo voltado para a saúde mental, e na sua concepção o isolamento era necessário para a recuperação e socialização do doente. Como enumera Gondim (2001), as principais operações feitas por Pinel que fundamentavam a prática asilar, eram três: $1^{0}$ Isolamento do mundo exterior, de forma que o alienado pudesse ser dominado e não dominar; $2^{\underline{0}}$ Constituição da ordem no asilo, com uma estrutura hierárquica a ser obedecida, bem como de uma disciplina em relação ao uso do tempo e do espaço; $3^{0}$ Relação de autoridade e soberania entre o médico-auxiliares e o alienado por intermédio da vigilância.

As duas linhas de pensamentos eram efetivamente praticadas, mas ao longo dos anos, percebeu-se que nenhuma das duas atendia aos interesses dessa clientela e dificilmente propiciavam sua melhora; seus direitos não eram respeitados, além do que, eram isolados da sociedade. Assim, surgiu a idéia da reforma psiquiátrica, na qual o intuito era fazer com 
que o tratamento demorasse o menor tempo possível e que os “doentes” deixassem as instituições psiquiátricas e voltassem ao convívio familiar e social.

\subsection{O Avanço da Psiquiatria e sua Reforma}

Desde o início da Idade Média os portadores de transtornos mentais tiveram suas vozes anuladas, abafadas, desvalorizadas e sem importância. Eles eram descartados da justiça, da responsabilidade de um ato ou de um contrato, e até mesmo a comunhão na Santa Missa, segundo Tundis (2000).

Somente no século XIX as pesquisas da medicina avançaram nos estudos sobre a Biologia, a partir da qual a doença mental começa a ser entendida como sendo de ordem neurocerebral, ou seja, os processos mentais seriam explicados com base no sistema nervoso, de acordo com Gondim (2001). Desta forma, a loucura passou a ser medicada. As degenerescências que os pacientes sofriam poderiam ter diversas causas: hereditariedade, influências sociais, doenças congênitas, entre outras, passando a ser vista não mais como distúrbio moral e sim como anormalidade. Assim, nasce a psiquiatria sendo uma doença específica, portanto, requer um saber médico específico, técnica e métodos também específicos, como explicita Tundis (2000).

Para esses tratamentos específicos, os "loucos” passam a ter um espaço isolado para eles manicômios - que viria a ser uma reclusão da sociedade externa, eram então, individualizados e disponibilizados para estudos. Assim, esses locais constituíram o que se pode chamar de prática médica, onde o foco do objeto de estudo da psiquiatria era a doença mental. A internação e o isolamento eram colocados como uma necessidade urgente e absoluta, tanto para a segurança do próprio doente, como da família e da sociedade, que para a tranqüilidade da população em geral, esta necessidade era ainda mais urgente para os indivíduos que pertencessem às classes sociais economicamente menos favorecidas, fruto do puro preconceito.

Ao decorrer do tempo, ainda de acordo com estudos de Tundis (2000) foi constatado que esses espaços - manicômios - excluíam os doentes do mundo, não lhes permitindo os mínimos direitos, e dificilmente propiciavam a reconstrução da pessoa e o tratamento eficaz da doença, pois uma vez que o paciente recebia a tão sonhada alta voltava em pouco tempo a ser internado novamente. O que se verificou, ao longo do tempo, é que a influência, sobretudo repressora e alienante dessas instituições provocava, muitas vezes, novos sintomas, que levavam os doentes a cronicidade. Portanto, era preciso transformá-la e reformá-la.

Essa reforma almejada por alguns seguimentos, pode ser analisada através de um tratamento multidisciplinar na qual uma equipe de profissionais de diversas áreas atuaria de maneira a estimular as relações e atividades que os pacientes teriam, estimulando a qualidade de vida em um ambiente "hostil”, além de otimizá-lo. 


\section{O PROFISSIONAL DE LAZER E A REALIDADE DE UM HOSPITAL PSIQUIÁTRICO}

\subsection{A Contribuição do Profissional de Lazer}

Não se pode discordar hoje em dia, de que uma das metas prioritárias no campo da assistência psiquiátrica, no Mundo, é a inversão do padrão atual de atendimento, que ainda é fundado no tratamento a base de medicamentos e do isolamento. Não se deve negar o efeito positivo do uso de algumas "drogas" para controlar a ansiedade, agressividade, entre outros "surtos" que o paciente possa apresentar, mas também se deve levar em conta que apenas esses tratamentos não respondem eficazmente ao que se pode chamar de tratamento humanitário, o qual depende da interligação que existe entre a psiquiatria e as outras áreas de intervenção que possam contribuir para melhorar a qualidade de vida desses pacientes, que precisam para um resultado melhor no tratamento, geralmente, ficar internos.

Essa interligação deve ser feita através de profissionais de várias áreas como assistentes sociais, psicólogos, terapeutas, enfermeiros, além dos médicos, e ainda visualiza-se a necessidade da intervenção de profissionais ligados a área social e cultural - para esse tratamento diferenciado, os profissionais de lazer têm destaque. Esses profissionais devem proporcionar vivências lúdicas para despertar destrezas e interesses aos pacientes.

Quando se fala em interesses que os profissionais de lazer devem proporcionar, remete-se à classificação de Dumazedier (1980), que coloca como sendo interesses artísticos, aqueles ligados as festas tradicionais, cinema, teatro, música, ficção e as artes plásticas; interesses intelectuais, ligados pela religiosidade, leitura, ao conhecimento vivido; interesses físicos, todas as atividades que demandam esforço físico, movimento; interesses manuais, ligados à capacidade de transformar objetos, como artesanato, "bricolage”, jardinagem, artesanato; interesses sociais, nos quais há os contato face-a-face, os relacionamentos interpessoais, a busca de divertimento e informação através dos pares. É importante que as atividades de lazer procurem atender a todos os indivíduos e seus interesses pessoais, para isso, é necessário através do profissional de lazer, que os indivíduos conheçam as atividades que os satisfaçam e a escolha da atividade só será possível se houver conhecimento das várias alternativas que o lazer oferece.

Os profissionais de lazer atuam como mediadores entre o patrimônio cultural, das artes, da filosofia e das ciências, e da cultura vivida no cotidiano, constroem as bases que viabilizam o movimento de democratização cultural, e através das suas ações, baseados nos valores da Revolução Cultural do Lazer, é que esse movimento passa a se concretizar, introduzindo os estímulos necessários ao processo de mudança, que é o principio desta Revolução, definida, sobretudo como um esforço de conscientização sócio-cultural, da mudança entre os valores nos últimos anos.

Levando esse aspecto e característica do profissional de lazer para a esfera num contexto hospitalar, o profissional deve saber enfrentar as divergências entre os parâmetros usados para o tratamento moral e social dos portadores de transtorno mental. É preciso, mais do que um tratamento medicamentoso, é preciso um tratamento social, um tratamento humanitário, não excluir os excluídos, fazer com que esses pacientes tenham oportunidades de vivências, não só do lazer, mas de todo o contexto social, promovendo a inclusão dos mesmos na sociedade. 
Esses indivíduos devem ser tratados com mais respeito, visto que fazem parte de um todo. Percebe-se o quanto ainda é grande o preconceito da sociedade com os mesmo; prova disso é que, a maioria dos indivíduos, ditos "normais" discriminam sem nunca terem entrado em uma instituição psiquiátrica e muitas vezes condenam quem já esteve. Os portadores precisam ser considerados iguais aos outros, tendo principalmente os mesmos direitos, como saúde, educação, segurança e lazer.

Analisando melhor o direito ao lazer, é necessário que os indivíduos conheçam as atividades que satisfaçam seus interesses, sejam estimulados a participar e recebam um mínimo de orientação que lhes permita a opção caracterizadora do lazer - a livre escolha. Essa escolha só será possível se houver conhecimento das várias alternativas que o lazer oferece. Para isso, o profissional de lazer deve difundir as práticas dos interesses, para assim, os pacientes escolherem o que mais lhe agrada. O que se espera desse profissional atuando em instituições hospitalares é que seja capaz de proporcionar vivências de lazer otimizando o espaço hospitalar e aproveitando melhor o tempo disponível, e ainda possibilitar a integração da sociedade com os pacientes internados.

A contribuição desse profissional fica bem caracterizada com as palavras de Oliveira (2001, p. 1), que visualiza algumas das possibilidades de transformações que podem ser decorrentes da inserção do lazer em hospitais:

No contexto hospitalar, a recreação se faz necessária não só para amenizar a permanência do paciente no hospital, mas também para estimular a socialização, a afetividade, o bem estar físico e mental, enfim, o resgate da parte saudável do paciente e a sua qualidade de vida.

E ainda como afirma Soares (2001, p.7), “o gesto lúdico, o brincar, a brincadeira são dimensões da construção da linguagem humana e permitem a expressão, representação, significação e (re)significação do movimento”. Assim, pode-se perceber que a vivência do lazer em instituições hospitalares é de extrema importância, pois ele além de ser amenizador de conflitos e tensões permite ao "ser" identificar-se enquanto portador de vontades e de habilidades para desenvolver as atividades que estiverem ligadas aos seus interesses.

\subsection{Vivências de Lazer na Medicina Psiquiátrica}

A instituição observada possui em seu quadro de funcionário cerca de 440 profissionais, entre os quais observam-se enfermeiros, técnicos de enfermagem, psicólogos, terapeutas ocupacionais, assistentes sociais, nutricionistas, cozinheiros, médicos, administradores, além dos profissionais do departamento de Recursos Humanos, da direção, da segurança e de limpeza.

A instituição possui atendimento rotativo, ou seja, os pacientes são internados de acordo com a situação e gravidade do transtorno mental apresentado e depois, quando tratados voltam para a sociedade. Atualmente, a instituição atende cerca de 200 pacientes por dia, incluindo a emergência, o Hospital-dia e o próprio Hospital. Além dos pacientes portadores de transtorno mental, são atendidos viciados em drogas, alcoólatras, e etc. Os pacientes internos são divididos nas enfermarias masculinas e femininas. 
Na instituição, observa-se ainda a presença de pacientes internados há mais de 40 anos, chamados de residentes, isso se deve, principalmente, ao fato de a família discriminar e abandoná-lo, possui também os crônicos, que apresentam transtorno mental agudo, os de primeira internação e aqueles que depois de deixar as dependências do hospital, após algum tempo voltam a ser internados. O que se percebe muito é a preocupação de fazer com que os pacientes de primeira internação não voltem a ser internados.

Analisando os espaços do hospital estudado percebe-se que o mesmo possui algumas áreas que poderiam ser melhor aproveitadas, como a quadra central e as quadras das enfermarias masculina e feminina que se encontram abandonadas, sem manutenção e sem políticas de atividades, para isso o profissional de lazer se faz necessário, visto que saberá enfrentar as divergências e conseguir estimular vivências otimizando os espaços.

Na quadra central o que deveria ser feito, é uma utilização mais adequada aos interesses coletivo com apresentações de interesses artísticos e culturais que viabilizariam principalmente, a integração da sociedade com os pacientes, seria um processo de inclusão inverso, na qual, ao invés de incluir os pacientes na sociedade a sociedade se incluiria no cotidiano dos pacientes; é uma forma, também, de proporcionar vivências lúdicas, visto que os pacientes se encontram internos e sem possibilidades de deixar o local para ter essas vivências em outros ambientes; e não só as mesas de jogos de sinuca, dominó e futebol, e a televisão que lá se encontram como forma de lazer. Já o espaço das quadras dentro das enfermarias deve ser otimizado, uma das várias possibilidades de intervenção é a utilização desses espaços pra a realização de torneios esportivos, atividades em grupo, estafetas e outras com os pacientes, fazendo a integração entre as alas das enfermarias, estimulando o convívio com os pares através do divertimento e desenvolvimento.

O hospital possui também uma sala de recreação na enfermaria masculina e na feminina, onde são desenvolvidas as oficinas terapêuticas pelos profissionais do próprio hospital e pelos estagiários de Terapia Ocupacional. É interessante observar que as escolhas das atividades desenvolvidas nas oficinas variam entre os grupos feminino e masculino; os homens preferem fazer pinturas, reciclagem, atividades com jornais, enquanto as mulheres preferem tapetes de retalhos, fuxico, crochê, ambos tendo preferência por atividades de interesses manuais.

O ambiente das salas de recreação não é muito agradável, deveriam ser otimizados, pintados pelos próprios pacientes, sendo mais uma vivência de lazer e ainda deixaria o ambiente mais alegre, com vida, mais iluminado, com a ajuda dos próprios pacientes que são os principais beneficiados com a mudança. É importante que o espaço onde são realizadas as vivências seja adequado e que faça com que o indivíduo tenha vontade de permanecer nele.

O hospital também possui um campo de futebol - interesse físico do lazer - que é utilizado pelos pacientes nas segundas-feiras pela manha; as atividades são desenvolvidas pelos profissionais de enfermagem que coordenam a vivência e esporadicamente e fazem torneiros com outras instituições. As condições do campo são muito boas, a manutenção é constante, é gramado, possui traves e irrigação e os pacientes desenvolvem habilidades como coordenação motora, raciocínio, cooperação e socialização. 
Outro espaço de vivência do lazer é a horta, que é cuidada pelos próprios pacientes que se interessam pela atividade. A horta já possui vários frutos e sementes, como tomate, alface, pimenta e outros, que servem para a própria alimentação deles, sendo considerado um interesse manual do lazer..

Também é atividade do hospital o passeio a um parque ecológico, nas segundas-feiras à tarde, mas não são todos os pacientes que são liberados para o passeio, apenas aqueles com autorização dos médicos. No parque eles caminham, conversam, contam histórias e cantam, se tratando do interesse social do lazer.

Nas terças-feiras pela manhã acontece o Louvor. Pessoas que fazem trabalhos voluntários vão ao hospital desenvolver essa vivência; e nas quintas-feiras pela manhã o forró; a administração da terapia ocupacional coloca o som e os pacientes dançam e se divertem na quadra central - interesse físico e social. As tardes de terça a sexta são liberadas para a visita dos parentes após as 15h, pois antes desse horário acontece a medicação.

Visualizando a necessidade de um profissional de lazer no âmbito hospitalar, o mesmo é capaz de modificar a realidade dessas instituições através de vivencias lúdicas, melhorando a qualidade de vida do grupo; as intervenções lúdicas podem representar a realização de ações coletivas, construindo possibilidades para que os pacientes possam vivenciar experiências diversificadas, construir simbolicamente a realidade, criar e recriar o mundo que os cerca. Assim, para Oliveira (2001, p. 2):

Quando o enfermo produz algo seja material ou simplesmente a solução para um problema proposto, se sente útil, produtivo, menos doente. Nessa perspectiva, a recreação contribui - e muito para o tratamento, visto que pode despertar no paciente a vontade e a crença na melhora, acelerando assim o tratamento.

No entanto, a vivência do lazer, não tem como objetivo principal estancar o quadro de incertezas, medo, e tristeza, existente em hospitais, e sim despertar novas possibilidades para a vivência social e cultural, e para o desenvolvimento social do grupo, por meio do lazer. Fazê-los vivenciar situações e realidades diferentes, distantes da sua realidade dentro do hospital, assim como realizar um programas de jogos e atividades, na qual eles terão a chance de se expressar de uma maneira nova, pouco ou nunca experimentada, também fará com que haja uma mudança significativa nos seus comportamentos, e conseqüentemente a melhora no seu quadro clínico.

Assim, avalia-se que a atuação do profissional de lazer no âmbito hospitalar é tão importante para a instituição, pois otimiza os espaços nela encontrados, quanto para os pacientes, pois é disponibilizada para eles vivência que os levam a uma melhora no quadro clínico, para a sociedade, que ganha com um profissional capacitado para diminuir o hiato entre um hospital de segregação de indivíduos e a sociedade, e para a família, por ter um alguém preparado para instruir o paciente e fazê-los vivenciar atividades do cotidiano. 


\section{CONSIDERAÇÕES}

As considerações e a possibilidade de resolução, mesmo que parcial, acerca de um problema comum encontrado na sociedade brasileira - a segregação de indivíduos portadores de transtorno mental - é deveras importante tanto para otimizar a inclusão desses indivíduos na sociedade, quanto para os próprios indivíduos que encontram no lazer, um aliado ao seu tratamento.

Para a constatação das necessidades dos portadores de transtorno mental com relação às atividades que ocupem seu tempo ocioso e ainda que despertem os seus interesses interesses culturais do lazer - mostra-se que o profissional de lazer é suficientemente capaz de intervir e transformar essa realidade, estimulando as vivências lúdicas, que indiretamente podem ser consideradas terapêuticas. E ainda, sendo ele - o lazer - capaz de promover mudanças na realidade de um hospital através de sua intervenção estimulando a socialização entre os pacientes e os indivíduos que os cercam, a inclusão social, e ainda contribuindo para a melhora da qualidade de vida dos pacientes e conseqüentemente para a melhora no quadro clínico do mesmo.

Tendo em vistas as atividades orientadas por um profissional de lazer com fins lúdicos, pode-se perceber que as atividades grupais são as mais indicadas no caso de serem realizadas em instituições hospitalares segregadoras por estimularem várias vivências e contribuírem para um melhor desempenho nas atividades, desde o momento em que o paciente passivo decide interagir - tornar-se ativo - quanto no que concernem as quebras de paradigmas acerca do convívio e da utilização dessas vivências como forma de tratamento da doença.

Buscando atender aos objetivos do presente estudo sobre humanização hospitalar através do profissional de lazer, no que tange aos espaços com possibilidades para se vivenciar o lazer, o hospital analisado possui vários espaços para a realização de atividades de lazer, ainda que nem todos os espaços sejam utilizados da melhor maneira possível e mais aproveitável para os pacientes, no momento, ficando suas políticas de animação a cargo de profissionais de outras áreas, como os enfermeiros, técnicos de enfermagem, assistentes sociais e terapeutas ocupacionais, os quais não possuem competência acadêmica para tal.

O estudo demonstrou-se extremamente necessário na conjuntura atual brasileira, na qual a sociedade ainda discrimina os pacientes portadores de transtorno mental e não disponibiliza para eles um convívio com os pares no dia-a-dia fora do cotidiano dessas instituições, sendo assim, o profissional de lazer tem como dever incentivar essa convivência através da inclusão social, que possibilita a diminuição do hiato existente entre sociedade e hospital.

Para o futuro, pretende-se que este estudo não seja apenas uma utopia, mas sim que o mesmo possa contribuir de forma a melhorar a qualidade de vida desses pacientes e envolver mais profissionais que se dediquem a essa causa, convergindo para que a sociedade se envolva nas questões sociais ainda pendentes no cotidiano.

Deseja-se com este que outros estudos sobre o tema sejam realizados e disponibilizados, visualizando que o lazer pode sim modificar uma realidade e contribuir para qualidade de vida, e ainda, mesmo que indiretamente, é considerado uma alternativa terapêutica, que proporciona a melhora no quadro clínico dos pacientes, e ainda para a disseminação de 
conhecimento e conteúdo relativos a todos os indivíduos da sociedade, e ainda a crença de que em um futuro próximo não mais as instituições hospitalares psiquiátricas excluam e isolem o paciente do convívio sociocultural, que o preconceito com o portador de transtorno mental diminua, para assim poder-se viver em harmonia com toda sociedade. E que o tratamento para esses pacientes, evolua de maneira a minimizar o isolamento e possibilitar aos que eles tenham todos os seus direitos e deveres sendo efetivamente cumpridos.

\section{BIBLIOGRAFIA}

CAMARGO, Luiz Octávio de Lima. Educação para p Lazer. São Paulo: Editora Moderna, 2002.

DUMAZEDIER, Joffre. Valores e Conteúdos Culturais do Lazer. São Paulo: SESC, 1980.

Sociologia Empírica do Lazer. São Paulo: Perspectiva: SESC, 1999.

GOMES, Christianne Luce (org). Dicionário Crítico do Lazer. Belo Horizonte: Autêntica, 2004.

GONDIM, Denise Saleme Maciel. Análise da implantação de um serviço de emergência psiquiátrica no município de Campos: inovação ou reprodução do modelo assistencial? 2001. 130p. Dissertação (Mestrado em Saúde Pública) - Fundação Oswaldo Cruz: Escola Nacional de Saúde Pública, São Paulo, 2001. Disponível em: $<$ http://portalteses.cict.fiocruz.br/transf.php?script=thes_cover\&id=000010\&lng=pt\&nrm= iso\#top>. Acesso em: 8 out 2004.

JULIO, Michelle Souza; PELLEGRIN, Ana De. Recreação com fins terapêuticos. In: ENCONTRO NACIONAL DE RECREACAO E LAZER, 14., 2002, Santa Cruz do Sul. Anais... Santa Cruz do Sul: Universidade de Santa Cruz do Sul, 2002.

LYRA, Paulo de Tarso. O calvário dos hospitais psiquiátricos. Brasília: [s.n.], [200-]. Disponível em:< http://www.crprj.org.br/clip004.htm>. Acesso em: 8 out de 2004.

MARCELlinO, Nelson Carvalho. Lazer e Humanização. 6a ed. São Paulo: Papirus, 1995.

MOREIRA, Wagner Wey (Org.). Qualidade de Vida: complexidade e educação. Campinas, SP: Papirus, 2001.

OLIVEIRA, Gilson Lima De. Experiência de recreação com crianças portadoras de sofrimento psíquico. In: ENCONTRO NACIONAL DE RECREACAO E LAZER, 13., 2001, Natal. Anais... Natal: CEFET-RN, 2001.

SOARES, Amanda Fonseca; ISAYAMA, Helder Ferreira. A construção de vivencias lúdicas com crianças que passam por tratamentos hospitalares: limites e possibilidades. In: ENCONTRO NACIONAL DE RECREACAO E LAZER, 13., 2001, Natal. Anais... Natal: CEFET-RN, 2001.

TUNDIS, Silvério Almeida; COSTA, Nilson. Cidadania e Loucura: políticas de saúde mental no Brasil. 6 ${ }^{\text {a }}$ ed. Petrópolis: Vozes, 2000. 
WITIUK, Ilda Lopes; SILVA, Neusa Castro Rosadas. Dificuldades para implantação do processo de (des) hospitalização do portador de transtorno mental. Curitiba: PUCPR, [19--]. Disponível em: < http://www.cpihts.com/2003_07_06/Ilda_lopes.htm>. Acesso em: 6 out 2004. 